\title{
Erratum
}

\section{The acetylation of RelA in Lys310 dictates the NF-kB-dependent response in post-ischemic injury}

Cell Death and Disease (2010) 1, e107; doi:10.1038/cddis.2010.88; published online 9 December 2010

Correction to: Cell Death and Disease (2010) 1, e96; doi:10.1038/cddis.2010.76; published online 4 November 2010

A Lanzillotta ${ }^{1}$, I Sarnico ${ }^{1}$, R Ingrassia ${ }^{2}$, F Boroni ${ }^{1}$, C Branca ${ }^{1}$, M Benarese ${ }^{1}$, G Faraco $^{3}$, F Blasi $^{3}$, A Chiarugi $^{3}$, PF Spano ${ }^{1,4}$ and M Pizzi*, ${ }^{\star, 4}$

1 Division of Pharmacology and Experimental Therapeutics, Department of Biomedical Sciences \& Biotechnologies, School of Medicine, University of Brescia and Istituto Nazionale di Neuroscienze-Brescia, Brescia, Italy
2 Department of Obstetrics and Gynecology and Biomedical Technologies, University of Brescia, Brescia, Italy 3 Department of Pharmacology, University of Florence, Florence, Italy

4 Istituto Ricovero e Cura a Carattere Scientifico, S. Camillo Hospital, Venice, Italy

Since the publication of the above article, the authors have identified that the numbering and order of affiliations were incorrect. The correct affiliation details are shown above.

We would like to apologize for any inconvenience this may have caused. 